\title{
A PRÁtICA DE ENFERMAGEM NA ATENÇÃO À SAÚdE DA CRIANÇA EM UNIDADE BÁSICA DE SAÚDE
}

Glória Lúcia Alves Figueiredo ${ }^{2}$

Débora Falleiros de Mello ${ }^{3}$

Figueiredo GLA, Mello DF. A prática de enfermagem na atenção à saúde da criança em unidade básica de saúde. Rev Latinoam Enfermagem 2003 julho-agosto; 11(4):544-51.

Este estudo tem como objetivo identificar as ações de enfermagem no acompanhamento do crescimento e desenvolvimento de crianças menores de cinco anos de idade, usuárias de duas Unidades Básicas de Saúde de Franca-SP. O estudo empírico foi baseado em observação, através de videogravação, das atividades de enfermagem nos setores de vacinação, pré-consulta, pós-consulta e coleta para o teste do "pezinho". Depreendemos que as ações básicas de acompanhamento do crescimento e desenvolvimento, de estímulo ao aleitamento materno, orientações alimentares, vacinação, prevenção de doenças prevalentes estão permeando a assistência de enfermagem, embora de forma fragmentada na comunicação e vínculo com a clientela.

DESCRITORES: cuidados primários de saúde; enfermagem; criança

\section{NURSING PRACTICE IN CHILDREN HEALTHCARE AT A BASIC HEALTH UNIT}

This study aimed at identifying nursing actions in the follow-up of growth and development of children under five years old who were assisted at two Basic Health Units in Franca, Brazil. The empirical study was based on observation of nursing activities in the vaccination, pre-consultation, post-consultation and newborn screening test collection sectors, using video recording. We concluded that basic follow-up actions concerning growth and development, breastfeeding stimulation, food orientation, vaccination and prevalent disease prevention are permeating nursing care, although in a fragmented way in communication and ties established with clients.

DESCRIPTORS: primary health care; nursing; child

\section{LA PRÁCTICA DE ENFERMERÍA EN LA ATENCIÓN A LA SALUD DEL NIÑO EN UNIDAD BÁSICA DE SALUD}

Este estudio tiene como objetivo identificar las acciones de enfermería en el acompañamiento del crecimiento y desarrollo de niños menores de cinco años de edad, usuarios de dos unidades básicas de salud de Franca-SP. El estudio empírico fue basado en la observación, a través de video grabación de las actividades de enfermería en los sectores de vacunas, preconsulta, post consulta y test para detección de Hipotireoidismo Congénito y Fenilcetonuria. Verificamos que las acciones básicas de acompañamiento de crecimiento y desarrollo, del estímulo a la lactancia materna, orientaciones alimentares, vacunas, prevención de enfermedades prevalentes están permeando la atención de enfermería, aunque de forma fragmentada en la comunicación y vínculo con la clientela.

DESCRIPTORES: atención primaria de salud; enfermería; niño

\footnotetext{
${ }^{1}$ Este trabalho é parte da Dissertação: Figueiredo GLA. A enfermagem no acompanhamento do crescimento e desenvolvimento infantil em Unidade básica de Saúde: fragmentos e reconstruções. [dissertação]. Ribeirão Preto (SP): Escola de Enfermagem de Ribeirão Preto/USP; 2001;

${ }^{2}$ Enfermeira, Mestre em Enfermagem em Saúde Pública, e-mail: zedealenca@uol.com.br; ${ }^{3}$ Professor Doutor da Escola de Enfermagem de Ribeirão Preto, da Universidade de São Paulo, Centro Colaborador da OMS para o desenvolvimento da pesquisa em enfermagem
} 


\section{O acompanhamento do crescimento e} desenvolvimento de crianças menores de 5 anos é complexo e pretende-se aqui olhar para esse processo destacando a enfermagem na atenção básica à saúde da criança, diante das transformações presentes no sistema de saúde brasileiro, a partir do processo de municipalização da saúde, tendo como perspectiva a atenção integral à saúde da criança, que pressupõe, além de uma assistência baseada em aspectos biopsicossociais, a criação de elos entre a população usuária e os serviços.

$\mathrm{Na}$ década de 80 , no Brasil, numa ação coordenada entre o governo federal, as Secretarias Estaduais e Municipais de Saúde e o Ministério da Saúde, baseado na análise das condições sanitárias e epidemiológicas da população, foi elaborado o programa de "Assistência Integral à Saúde da Criança", a fim de possibilitar a criação de elos entre a população e os serviços de saúde, através do acompanhamento sistemático do crescimento e desenvolvimento de crianças menores de 5 anos de idade. Os serviços deveriam estar preparados para resolver, a partir da unidade básica, a maioria dos problemas de saúde das crianças, inclusive os fatores indesejáveis do meio ambiente. Com enfoque na assistência integral à saúde da criança, cinco ações básicas surgiram como respostas do setor saúde aos agravos mais freqüentes e de maior peso na morbimortalidade de crianças de 0 a 5 anos de idade: Aleitamento Materno e Orientação Alimentar para o Desmame, Controle da Diarréia, Controle das Doenças Respiratórias na Infância, Imunização e o Acompanhamento do Crescimento e do Desenvolvimento $^{(1)}$.

Com o Programa de Assistência Integral à Saúde da Criança, de 1984, o Ministério da Saúde marcou uma diretriz política para expansão e consolidação da rede de serviços básicos, utilizando para isso a estratégia da assistência integral, buscando a integração das diferentes instituições envolvidas na prestação da assistência à saúde e utilizando atividades de baixa complexidade e baixos custos. O acompanhamento do crescimento e desenvolvimento infantil, através da sistematização de retornos ao serviço de saúde do recém-nascido ao adolescente, foi considerado o eixo integrador das ações básicas. se descentralizando, assim também as políticas de saúde, apontando as diretrizes para um novo e único sistema, o Sistema Único de Saúde pautado pelos princípios de universalidade, eqüidade, integralidade e organizado de maneira descentralizada, hierarquizada e com participação da comunidade. A proposta concebia a existência de uma rede básica de serviços de saúde, hierarquizada em relação à sua complexidade tecnológica em nível primário, secundário e terciário. Assim, o nível primário funcionaria como porta de entrada do sistema, oferecendo cuidados básicos de saúde, incluindo-se aí a atenção médica integral, referenciando os casos mais complexos para os demais níveis, propondo a universalidade da assistência, integração dos serviços e a municipalização da saúde, expandindo e consolidando a rede básica de saúde ${ }^{(2)}$.

O município passa, então, a ser eleito o local para planejamento e execução das ações de saúde. Na gestão municipalizada, são colocadas novas possibilidades para o reconhecimento dos problemas e necessidades locais de saúde, dentro da perspectiva da construção de uma vida saudável para a população. Atualmente, o Programa de Saúde da Família vem sendo proposto como estratégia do Ministério da Saúde com ênfase no envolvimento e proximidade entre serviços, trabalhadores da saúde e a família em uma área determinada.

Aliada às questões das políticas, dos programas e dos indicadores de saúde, a literatura vem contribuindo em muitos aspectos dos serviços de saúde. A área de saúde materno-infantil comporta um grande número de trabalhos científicos sobre atenção a saúde da criança e suas condições através de indicadores de saúde e socioeconômicos, estado nutricional infantil, doenças mais prevalentes na infância, vacinação, aleitamento materno e baixo peso ao nascer ${ }^{(3-5)}$; seguimento de crianças de risco $^{(6)}$, avaliação dos programas de assistência maternoinfantil $^{(7)}$, desempenho profissional na assistência primária à saúde da criança ${ }^{(8)}$ e aspectos sobre o modo de vida da mãe e a saúde dos filhos ${ }^{(9)}$. Alguns estudos têm enfocado o processo de crescimento e desenvolvimento e a forma como ele se realiza, caracterizando-o como um indicador positivo de saúde, dentro de uma perspectiva integrativa, ou seja, a criança vista como um ser humano em desenvolvimento ${ }^{(10)}$. Outro aspecto apontado na literatura é a apreensão desse processo enquanto vigilância à saúde, compreendida como eixo de reorientação do modelo assistencial do SUS, na tentativa de contemplar o 
paradigma da saúde centrado na qualidade de vida e desenvolvimento global das comunidades ${ }^{(11)}$.

A assistência à saúde da criança, inicialmente, foi baseada em ações programáticas, convergiu-se numa proposta de atenção primária reducionista provida por pessoal de baixa qualificação profissional e, com isso, a não efetivação das ações básicas, seja pelo despreparo técnico ou pelo reduzido número de trabalhadores ou pelo pequeno investimento político na atenção primária à saúde ${ }^{(12)}$.

A partir da municipalização da saúde, a enfermagem nas instituições de saúde ligadas ao SUS expandiu numericamente, assumiu ações, papéis, organizou e ocupou a gerência dos serviços, constituiuse em ator chamado a dar respostas às diretrizes políticas.

Entendemos que vários aspectos se entrelaçam no complexo trabalho desenvolvido na rede básica de serviços públicos de saúde e, neste estudo, o objetivo é identificar as atuais ações de enfermagem no acompanhamento do crescimento e desenvolvimento de crianças menores de cinco anos de idade, enfocando a comunicação com as mães, usuárias de duas Unidades Básicas de Saúde de Franca-SP.

\section{METODOLOGIA}

Esta investigação consiste em um estudo descritivo exploratório, que procura identificar as atuais ações de enfermagem na atenção à saúde da criança em UBS, através de videogravação. Esse tipo de estudo busca observar, descrever e documentar aspectos de uma situação que naturalmente ocorre, na perspectiva de uma abordagem qualitativa ${ }^{(13)}$. A videogravação transforma em imagens bidimensioanais uma realidade tridimensional, sua contribuição para a observação sistematizada e para a construção do conhecimento está na repetição da observação, melhorando a precisão com que o observador apreende o fenômeno ${ }^{(14)}$.

A observação através da videogravação esteve centrada nas ações de enfermagem realizadas com as crianças agendadas e na captação das falas entre os trabalhadores de enfermagem e mães/familiares das crianças atendidas nos setores de vacinação, pré-e pósconsulta e coleta do teste do "pezinho", em duas UBS de Franca-SP. Primeiramente, entramos em contato com a
Secretaria Municipal de Saúde de Franca, solicitando autorização para a realização do estudo e encaminhamos o projeto de pesquisa ao Comitê de Ética em Pesquisa da Escola de Enfermagem de Ribeirão Preto da Universidade de São Paulo, obtendo parecer favorável. Assim sendo, selecionamos duas UBS com base nos seguintes critérios de inclusão: possuir enfermeiro, técnico e auxiliar de enfermagem, utilizar o sistema de agendamento, ter setor de vacinação, realizar coleta para teste do "pezinho", ter maior demanda de clientes em pediatria, possibilitar a utilização de equipamento de filmagem e não ser local de trabalho do pesquisador.

De maneira geral, as UBS são semelhantes, as salas em boas condições de higiene, pintura, iluminação e ventilação. Utilizam prontuários, arquivo para o índice e cartão de agendamento. Vale ressaltar que a organização do agendamento é um procedimento bastante dinâmico e que não é de responsabilidade exclusiva do gerente local. A UBS, por pertencer à Secretaria Municipal de Saúde, segue o direcionamento político municipal, que por sua vez sofre mudanças, seja por pressões da população ou pelas prioridades políticas adotadas. A abordagem inicial com as mães foi realizada na área física destinada para sala de espera, onde foram explicados, individualmente, os objetivos da pesquisa, dando liberdade para participação e solicitando seu consentimento através de autorização por escrito.

Utilizamos câmera tipo JVC GZ-S5U, fixa, sobre um tripé e operador ausente, mantendo-se ao lado externo das salas. Acrescentamos à técnica um diário de campo, na tentativa de captar e complementar a observação das falas e dos momentos pertinentes aos objetivos do estudo. Foram filmados 12 trabalhadores de enfermagem (dois turnos) e 62 crianças em atendimentos nos setores escolhidos. A coleta de dados empíricos teve a duração de dez dias, subdivididos em dois para a sala de coleta do teste do "pezinho", quatro para as salas de pré- e pósconsulta e quatro para as salas de vacinação. O total da observação através das filmagens foi de quarenta horas.

Para a análise das atividades observadas, utilizamos a transcrição integral do registro das falas, identificando a interação entre os trabalhadores e a clientela. Após o registro minucioso do vídeo transcrito e de anotações do diário de campo, ordenamos os dados, passamos à leitura e releitura com o propósito de selecionar os momentos que se repetiam ou que tivessem destaque, procurando, assim, a regularidade ${ }^{(15-16)}$. 
OS MOMENTOS DO ACOMPANHAMENTO DO CRESCIMENTO E DESENVOLVIMENTO DA CRIANÇA EM UNIDADE BÁSICA DE SAÚDE

A coleta de sangue para o teste do "pezinho" é realizada pelo profissional enfermeiro. Esse procedimento proporcionou o "encontro" da mãe com o profissional, observamos a preocupação em transmitir informações para as mães acerca do teste do "pezinho", primeiras vacinas e amamentação. A seguir, apresentamos um momento do atendimento:

A enfermeira trouxe uma mãe, acompanhada pela tia. Fechou a porta. A tia foi direto ao divã para despir o RN, enquanto a mãe, na mesa, olhava a enfermeira preencher os papéis. Após esse preenchimento a mãe se levantou e segurando uma sacola de plástico encostou-se à porta do consultório. A tia, com o RN no colo, aproximou-se da enfermeira que colocava as luvas.

Enf.: - (olhou para a mãe) Pode ficar tranqüila mãe, o neném vai chorar você lembra que eu falei?

Tia - É, no exame do pezinho é assim mesmo!

Enf.: - Então, (olhando para a tia) você já está acostumada a segurar?

Tia - Tô, já segurei dois, esse é o terceiro. (Olhou para a mãe e disse) Cê vai tirar os pontos agora cedo, né Ângela?

Mãe - (balançou a cabeça confirmando).

Enf. - (sentada, abaixo, próxima ao $R N$ e olhando para o pezinho do RN, iniciou a coleta). Vai passar pelo médico, então? Pode chegar mais pra cima, mas sem apertar a perninha, tá? Só um minutinho!

Mãe - Tô até tremendo (contorceu, apertou a sacola e começou a chorar, junto com o RN).

Enf. - Como é que chama o neném?

Mãe - Lígia.

Enf. - Lígia, Oh! Lígia. Senta aí mãe (mostrou a cadeira, a mãe retirou um lenço da sacola e utilizou). Dói, né mãe? A gente sabe que a mãe fica apreensiva, tudo, né, mas precisa, é um preventivo. Tá acabando, tô na última bolinha, viu, mãe? A mãe, às vezes, chora também né? Cê tá amamentando, mãe?

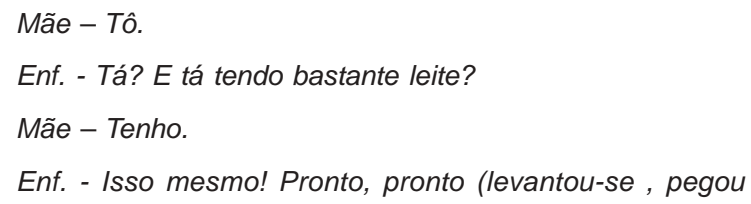
uma gaze e colocou no local da picada), aqui tem sangue adoidado, segura a gaze e não precisa apertar! Assim, e não precisa passar nada (a tia levou o RN até o divã para trocá-lo).

Mãe - Pode dar mamar?

Enf. - Pode, pode, deixa eu te dar o papelzinho (a segunda via do exame), e você vai procurar (o resultado) dia vinte e oito do quatro, tá?

Mãe - E as vacinas? Ela ainda não tomou.

Enf. - As vacinas é, vou escrever aqui pra você (atrás da segunda via do exame), as primeiras vacinas, toda quarta-feira das treze às quinze horas, tá?

Mãe - Esta vacina é quando ela tiver com um mês?

Enf. - Não, no primeiro mês de vida. Ela nasceu com três quilos e dez, né? Você já pode trazer quarta-feira agora, se não der mesmo, pode ser na próxima quarta-feira.

Mãe - Aí eu tenho que trazer algum cartãozinho?

Enf. - Não, o cartãozinho a gente faz na hora, tá bom?

$A$ aux. enfermagem abriu a porta interrompendo o atendimento:

Aux. - O dr. C. (g. obstetra) chegou!

A coleta de sangue para o "teste do pezinho" estava sendo realizada no consultório de g. e obstetrícia, pois estava vago e o horário do atendimento médico era mais tarde. A enf. lamentou balançando a cabeça:

Enf. - Como que eu vou fazer agora?

Aux. - Vou falar pra ele atender na pediatria! (saiu da sala).

Enf. - Tá (e continuou o atendimento).

$O$ atendimento foi interrompido novamente, dessa vez era o médico que abriu a porta, sem bater. A enfermeira levantou-se.

Enf. - Doutor, aguarde um minutinho só, por favor, que eu já converso com o senhor, tá? (Ele saiu e fechou a porta).

A enfermeira voltou a falar com a mãe, mas aumentou $o$ tom da voz e a velocidade da fala, pareceu nervosa. Continuou o atendimento em pé.

Enf. - Então a primeira vacina é toda quarta, viu? E o dia do retorno do exame já está marcado aí no papelzinho, tá?

Saíram da sala apressadamente, e a enfermeira mudou o local de atendimento, porque o consultório passaria a ser ocupado para as consultas médicas do ginecologista e obstetra.

Outro momento da filmagem foi o atendimento de pré- e pós-consulta. Essas atividades de enfermagem foram formalizadas no Estado de São Paulo, por ocasião das ações programáticas, que tinham a finalidade de controlar a doença na coletividade, visando ações que fossem além da consulta médica. No entanto, no modelo clínico de assistência sua execução favorece o diagnóstico, a terapêutica, a coleta e o registro de dados necessários ao desenvolvimento da consulta médica ${ }^{(17)}$. A seguir, descrevemos parte de dois exemplos desses atendimentos:

A auxiliar de enfermagem estava realizando uma pós- 
consulta, na sala destinada a essa atividade quando foi interrompida pela pediatra que parou na porta da sala de AE. A sala estava e permaneceu aberta durante o atendimento.

Aux. - Esse aqui (o medicamento) você dá... Oi doutora o Dr. J. (outro pediatra) ainda está atendendo...

Ped.: - Que número ele está?

Aux. : - Está no 14.

Ped. : - Então tá ocupado! E, no G.O.?

Aux.: - Só que eu não pesei nenhuma...

Ped.: - E o clínico?

Aux.: - Ele também está atendendo, eu já vou arrumar para a senhora (virou-se para a mãe e disse): aguarda um minutinho que eu já vou arrumar o aerosol pra você.

A auxiliar de enfermagem carimbou e entregou 0 medicamento sem acabar de orientar o uso do mesmo, saiu com a mãe, a criança e vários prontuários nas mãos. A servente entrou na sala trazendo prontuários e deixou-os sobre a mesa. Em seguida, chegaram duas mães com duas crianças, para a consulta médica, e a aux. de enfermagem.

Aux.: - (para a servente) Ela achou ruim que não pesei os meninos, eu falei pra ela que não tem condições...

A servente balançou a cabeça e saiu. Entrou uma mãe com uma criança, no colo, para a pós-consulta. Entregou a receita médica para a aux. de enfermagem.

Aux.: - Ah meu Deus! Ao invés de vir no horário dela (a pediatra)...

A mãe ouviu e permaneceu calada e próxima. A aux. de enfermagem leu a receita médica, foi até o armário, carimbou a receita e entregou o medicamento para a mãe, mas não orientou sobre o mesmo. Mãe e filho saíram da sala. Em seguida, chegaram duas mães com três crianças para a consulta médica. Uma mãe delas expressou a situação:

Mãe: - Hoje vocês estão apertadas, héin? (sorriu).

Aux.: - Ah, desse jeito não dou conta, né! Eles vêm na hora que eles querem, nossa, isso choca!

Mãe: - Por isso tinha que ter vindo de manhã, é menos freqüentado, não é? Hoje ta fogo, hein?

Aux.: - Acho que vou medir minha pressão, estou com uma dor na nuca... (saiu da sala).

Outro exemplo:

Na sala estavam a aux. de enfermagem e a téc. de enfermagem que organizava papéis. Chegou um pai com a filha, para a pós-consulta, pegou os medicamentos prescritos, carimbou, entregou e orientou o retorno e o uso. Atendimento realizado em pé na e com a porta da sala aberta.

Téc.: - Menina tá gorda, né ? Bonita! Essa pomada não tem, esse é o soro e a Novalgina, se tiver febre.

Pai: - Não tem em outro lugar?
Téc.: - Faz um mês que não tem, e se não tem aqui, em nenhum também não tem, e aqui se chegar é só daqui a 15 dias, e esse é o Adtil.

Pai: - E pra quê que é isso aí?

Téc.: - É uma vitamina, dá duas gotinhas por dia, até completar um ano de idade.

Pai: - Pinga na mamadeira?

Téc.: - Não, na boca, até completar um ano, e passa lá na recepção pra marcar retorno daqui um mês.

Pai: - Retorno?

Téc.: - É todo mês tem que marcar e voltar..

Saem da sala.

Finalmente, a filmagem dos atendimentos na sala de vacinas que seguem normas e padronização do Sistema de Vigilância Epidemiológica do Estado de São Paulo. As vacinas indicadas para crianças menores de cinco anos de idade seguem o Calendário de Vacinação de 1998 (BCG-Id, Contra Hepatite B, Tríplice Bacteriana - DTP, Dupla infantil, Contra Poliomielite, Contra Haemophylus influenzae, Contra Sarampo, Tríplice Viral e Contra a FebreAmarela), que são aplicadas diariamente, sem horário fixo, mas há a recomendação de que as mães compareçam entre 8 e 16 horas, com exceção do BCG-Id, realizado exclusivamente pela enfermeira, uma vez por semana. A seguir, descrevemos um atendimento na sala de vacinas:

Na sala estavam a auxiliar de enfermagem e a técnica de enfermagem, que sentada lia e determinava quais vacinas a criança iria receber, carimbava e organizava os registros de vacina, estatísticas, carteira e cartão controle de vacinas. A aux. de enfermagem foi até a porta e chamou, em voz alta, a criança a ser atendida. Ao entrar, em pé, ainda na porta:

Aux.: - Que idade tá o Thales?

Mãe 1: - Sete meses.

A mãe entrou, colocou a bolsa na cadeira e ficou com o bebê no colo.

Mãe 1: - A vacina dele tá atrasada, ele tava com febre.

Aux.: - É. E, tem Hepatite e Meningite também.

Mãe 1: - É... e ele tá gripado, tem problema?

Téc.: - Só não pode estar com febre.

Mãe 1: - Não, febre ele não tá não.

Aux.: - Hoje tem três injeções e a gotinha: Hepatite, Meningite e Tríplice e a Sabin.

Mãe 1: - Elas dão reação?

Aux.: - Ele já tomou duas, ele teve reação?

Mãe 1: - Não. Ah, ele teve na última.

Aux.: - É, e o que ele teve?

Mãe 1: - Na última ele ficou enjoado.

Aux.: - Ele ficou enjoado? É o da poupança, porque os da perninha é só na hora. Pode arrumar o neném! 
A mãe 1 foi até a cadeira, sentou-se e deitou o bebê no colo.

Aux.: - Vamos começar pelas perninhas. Põe ele sentado no seu colo.

A auxiliar de enfermagem abriu a geladeira de vacinas, rapidamente, preparou duas vacinas e aplicou nas duas coxas da criança. Limpou o sangue e colocou um pedaço de micropore nos locais das picadas. A mãe abraçou e beijou o filho.

Mãe 1: - Acabou agora, ou não?

Aux.: - Não! agora é no bumbum. Mãe essa aqui que é enjoadinha, viu? (aplicou).

A sala permaneceu com as portas abertas. Chegou a recepcionista, perguntou sobre a enfermeira e saiu. A auxiliar de enfermagem foi até a geladeira, pegou o frasco da Sabin pingou as gotinhas na boca do bebê e entregou a carteirinha de vacinas.

Aux.: - Oh! a Hepatite e a Meningite terminou, viu? Agora só o Sarampo, viu?

A mãe levantou-se, pegou a carteira de vacinas e leu.

Mãe 1: - Deixa eu te falar, a vacina contra a gripe é com que idade?

Aux.: - É só a partir de nove meses, (se dirige à téc.) não é?

Téc.: - Não, é a partir de um ano (e saiu da sala para chamar outra mãe).

Mãe 1: - Nossa, porque ele fica muito resfriado é todo mês...

Aux.: - Leva no Pediatra, pra ver uma vitamina $C$, ou alguma coisa assim, pra resistência.

Mãe 1: - Tá! Tchau.

Esses exemplos conformam um conjunto de situações empíricas significativas sobre o tema das ações de enfermagem no acompanhamento do crescimento e desenvolvimento da criança em UBS.

\section{DISCUSSÃO}

Em geral, os atendimentos foram com as "portas abertas" e rápidos. O espaço físico (as portas abertas, as salas com mais de uma atividade e a disposição dos móveis), a ausência de olhares, a técnica tomada como meio e fim nela mesma, a demanda, os diálogos fragmentados, orientações incompletas e atendimentos simultâneos foram aspectos que comprometeram a comunicação, em alguns casos não se ouviam as informações, diminuíram as respostas e houve distanciamento entre os sujeitos. Acreditamos que esses são alguns elementos que trazem fortes restrições ao diálogo, ao cuidar no ato assistencial e a intervir, efetivamente, sobre as necessidades apresentadas.

A pré- e pós-consulta são atividades realizadas pelo auxiliar e técnico de enfermagem. Observamos que atuaram com grande número de atendimentos, houve acúmulo de consultas em determinados períodos, atendimentos simultâneos, os diálogos foram "abertos" e fragmentados. Esteve centrado na verificação dos dados antropométricos e entrega de medicamentos.

Apreendemos que a organização desse atendimento se dá sob tensão, de um lado o cliente solicitando o atendimento, pois já está na fila de espera, e do outro lado o profissional médico solicitando os prontuários e a verificação dos dados antropométricos para iniciar as consultas. O stress compromete $o$ atendimento, o diálogo, o acolhimento, enfim, o cuidar.

O processo de trabalho em saúde coletiva nos programas de proteção e assistência à criança, oferece maior oportunidade para a enfermagem atuar ${ }^{(14)}$, sobre essa afirmação, o autor tece considerações específicas referentes à prática de enfermagem. As oportunidades de visualização do seu objeto de trabalho com determinações mais ampliadas e concretas são perdidas, como as relacionadas às condições de existência da criança e sua família, moradia, escolaridade, nutrição, trabalho, sendo que poderiam desenvolver um instrumental para atuar em saúde independente de critérios patológicos, e que lhe proporcionariam maior autonomia em relação ao médico, dentro do processo coletivo de trabalho em saúde.

As ações de saúde referentes a diagnósticos precoces e/ou aleitamento materno são mais eficazes quando $o$ atendimento se realiza nos primeiros dias de vida, nele deve inclusive discutir as ansiedades da mãe quanto à criança de um modo geral: incentivo ao aleitamento materno, controle da diarréia e hidratação oral, controle das doenças respiratórias, vigilância do crescimento e desenvolvimento, imunização básica ${ }^{(18)}$.

Durante os atendimentos de enfermagem, em todas as categorias, identificamos focos de atuação nos quais há um desejo de aproximação quando demonstram preocupação com o outro para além das técnicas como nos exemplos:...a gente sabe que a mãe fica apreensiva....às vezes chora...menina tá gorda...bonita!...e o que ele teve?... Mas há receios e, portanto, restringem suas atividades a ações bem definidas tecnicamente. Percebemos que a enfermeira faz corretamente as coletas, procura atender bem a clientela, orienta e organiza o serviço, mas possui uma 
rotina muito rígida, cumpre obrigações, se submete às ordens instituídas e está sempre envolvida em um cotidiano muito tarefeiro, é pressionada por uma demanda imposta, sem limites. E, o que não dá para fazer agora ela deixa para fazer depois, priorizando o trabalho de outros profissionais. De modo geral, realiza um atendimento e também outras solicitações, simultaneamente, com isso perde oportunidades para o cuidar, fragmentando o seu diálogo e $o$ atendimento, enquanto a mãe continua aguardando respostas.

Eticamente, é um direito do paciente o acesso a qualquer informação sobre seu corpo, mente, doença, alternativas terapêuticas, entre outros aspectos, e também porque o autoconhecimento amplia a eficácia da cura. Seria fundamental considerar como tarefa indispensável dos profissionais a transmissão de conhecimentos, ampliando a autonomia e reforçando a condição de sujeitos sociais, capazes de se autocuidar e de cobrar das instituições o atendimento às suas necessidades ${ }^{(8)}$.

Apreendemos, portanto, que as atuais ações de enfermagem na atenção à saúde da criança em UBS voltam-se às ações básicas de acompanhamento do crescimento e desenvolvimento: imunização, aleitamento materno, orientações alimentares, atividades de pré e pósconsulta, em procedimentos básicos (medidas antropométricas, medicações), agendamento, orientações individuais e grupais, bem como ações administrativas.

\section{CONCLUSÃO}

No presente estudo, a observação através de videogravação esteve centrada nas atividades de enfermagem realizadas com as crianças agendadas nas duas Unidades Básicas de Saúde escolhidas, e na captação das falas entre trabalhadores de enfermagem e mães/familiares das crianças atendidas nos setores de vacinação, pré- e pós-consulta e coleta do sangue para o teste do "pezinho". Em função do movimentado cotidiano de uma UBS, com atividades e diálogos simultâneos, depreendemos que a videogravação permitiu atenuar dificuldades para observar, retornar ao registro, detalhar a observação, definir falas, atores e ações. Além disso, foi possível captar grande quantidade de registro em pouco tempo.

Em uma UBS a equipe de enfermagem poderia estar organizada para o primeiro atendimento da criança com ações educativas efetivas e de sensibilização, garantindo o vínculo da mãe/família com a UBS para o acompanhamento do crescimento e desenvolvimento, estimular a mãe a se envolver, a querer saber cuidar da saúde dos seus familiares e, de estarmos atentos para o autocuidado. Diálogos são essenciais para a busca da qualidade de vida, do autocuidado e da cidadania.

Acreditamos que, no atendimento da sala de vacinas, nas primeiras vacinas, deveríamos ousar, aprimorar a comunicação com a clientela e ir além da técnica de administração da vacina. Os retornos periódicos para vacinação e atendimento em pré- e pós-consultas possibilitam uma vinculação estreita entre o profissional de enfermagem e a mãe, facilitam o envolvimento e conhecimento de outras necessidades da criança e sua família, escolaridade, nutrição e trabalho, aspectos do cuidado integral à saúde da criança, porém é preciso intensificar a comunicação e o acolhimento para um papel efetivo da enfermagem.

As ações básicas da saúde da criança vêm sendo desenvolvidas, mas não de forma integrada, ou seja, acontecem em momentos diferentes, com orientações truncadas, somente diante da queixa apresentada, comprometendo visualizar a criança como um ser humano em desenvolvimento. É necessário, então, a reformulação dessas práticas nas ações básicas preconizadas, a promoção da prática de amamentação, diminuição dos índices de morbimortalidade, participação ativa para o aumento da cobertura vacinal preconizada, estimular o apego mãe-filho-família; organizar o seguimento infantil; capacitar os recursos humanos entre outros, e para isso é de extrema importância a participação da família no cuidado e as mães devem ser orientadas, incentivadas e estarem seguras dos cuidados com a criança. Portanto, é uma relação que se dá no processo de trabalho, no cotidiano do cuidado à criança, buscando a atenção integral à saúde, segundo perspectiva do Sistema Único de Saúde.

As dificuldades são inúmeras no cotidiano da UBS, visto que falta à equipe a conscientização da importância do seu papel transformador, que a partir de uma transformação interna, não somente técnico-científica, mas também de respeito às pessoas, de ouvir o que têm a dizer, de relações e de subjetividades, derrubando um pouco o modelo que está aí, mas com preparo para isso. É algo que deve ser construído em conjunto, entre profissionais e usuários. 


\section{REFERÊNCIAS BIBLIOGRÁFICAS}

1. Ministério da Saúde (BR). Assistência integral à saúde da criança: Ações básicas. Brasília. (DF): Ministério da Saúde; 1984.

2. Nemes FAA. A unidade básica e o sistema de saúde. In: Schraiber LB, Nemes MIB, Mendes-Gonçalves SRB, organizadores. Saúde do adulto: programas e ações na unidade básica. São Paulo (SP): Hucitec; 1996.

3. Monteiro CA. Saúde e nutrição das crianças de São Paulo: diagnóstico, contrastes sociais e tendências. São Paulo (SP): Hucitec; 1988.

4. Victora CG, Fachini LA, Barros FC, Lombardi C. Pobreza e saúde: como medir nível socioeconômico em estudos epidemiológicos de saúde infantil? 1ํㅡㄹ Congresso Brasileiro de Epidemiologia. Rio de Janeiro (RJ); 1990.

5. Monteiro CA. Saúde infantil: tendências e determinantes na cidade de São Paulo na segunda metade do século $X X$. Rev de Saúde Pública 2000; 34(6):1-4.

6. Penalva O. Seguimento de Bebês de alto-risco. Curso Nestlé de atualização em Pediatria; 1996. Manaus, Amazonas. Manaus: Serviço de Informação Científica Nestlé; 1996.

7. Tanaka OY. Avaliação do programa de assistência à criança da Secretaria da Saúde de São Paulo. [mestrado]. São Paulo (SP): Faculdade de Saúde Pública /USP; 1982.

8. Rocha SMM. O processo de trabalho em saúde e a enfermagem pediátrica: socialidade e historicidade do conhecimento. [tese]. Ribeirão Preto (SP): Escola de Enfermagem de Ribeirão Preto/USP; 1990.

9. Dytz JLG. O modo de vida da mãe e a saúde infantil: estudo realizado no Distrito Federal. [tese]. Ribeirão Preto (SP): Escola de Enfermagem de Ribeirão Preto/USP; 1998.

10. Ricco RG, Del Ciampo LA, Almeida CAN. Puericultura princípios e práticas: atenção integral à saúde da criança. São Paulo (SP): Atheneu; 2000.

11. Teixeira CF, Paim JS, Villas Bôas AL. SUS, modelos assistenciais e vigilância da saúde. IESUS 1998; 2(2):7-28. 12. Sucupira AC. Representando a atenção à saúde da criança e do adolescente na perspectiva intersetorial. Rev Administração Pública 1998; 32(2):61-78.

13. Polit DF, Hungler BP. Fundamentos de pesquisa em enfermagem. Porto Alegre (RS): Artes Médicas; 1995.

14. Carvalho AMA, Bergamasco NHP, Lyra MCDP, Pedrosa MIPC, Rubiano MRB, Rossetti-Ferreira MCT. Registro em vídeo na pesquisa em psicologia: reflexões a partir de relatos de experiência. Psicologia: Teoria e Pesquisa 1996; 12(3):261-7.

15. Bodgan R, Biklen S. Investigação qualitativa em educação: uma introdução à teoria e aos métodos. Porto (Portugal): Porto Editora; 1994.

16. Minayo MCS, Deslandes SF, Cruz O Neto, Gomes R. Pesquisa social. Petrópolis (RJ): Vozes; 1999.

17. Almeida MCP, Rocha SMM, organizadoras. O trabalho de enfermagem. São Paulo (SP): Cortez; 1997.

18. Campos WSC. Reforma da reforma: repensando a saúde. São Paulo (SP): Hucitec; 1997. 